\title{
ENGAJAMENTO OU ADIÇÃO AO TRABALHO? ESTUDO QUALITATIVO COM GESTORES DA CONSTRUÇÃO CIVIL
}

\section{ENGAGEMENT OR WORKAHOLISM? QUALITATIVE STUDY WITH CIVIL CONSTRUCTION MANAGERS}

Paola da Luz

Bacharel em Administração pelo Centro Universitário UNIVATES.

Lajeado, RS, Brasil

E-mail: pa_luz@hotmail.com

\section{Liciane Diehl}

Doutoranda em Psicologia (UNISINOS). Mestre em Psicologia Social (PUCRS). Especialista em Gestão Estratégica de Pessoas

(UNIVATES). Psicóloga (UNISINOS). Professora e Coordenadora Pedagógica do Centro de Gestão Organizacional do Centro

Universitário UNIVATES.

Lajeado, RS, Brasil

E-mail: lici@univates.com

Michelle Engers Taube de Oliveira

Mestranda em Psicologia (UNISINOS). Especialista em Psicologia Organizacional e do Trabalho (IDG). Psicóloga (URI). Professora de

Pós-graduação do Centro Universitário UNIVATES.

Lajeado, RS, Brasil

E-mail: michelletaube@hotmail.com

\section{RESUMO}

As exigências dirigidas aos gestores são consequência da transformação do mundo do trabalho, podendo levar ao aumento da jornada laboral e ao máximo envolvimento físico e mental. Esse estudo tem como objetivo avaliar a tendência de perfil dos gestores de uma empresa de construção civil, considerando os comportamentos de engajamento e adição ao trabalho. O método utilizado foi o descritivo, de abordagem qualitativa. Os dados foram coletados por meio de entrevistas semiestruturadas com seis gestores administrativos e foram analisados pela técnica de análise de conteúdo. Os resultados apontaram que os gestores apresentam uma tendência ao excesso de trabalho, extensão da carga horária laboral e desequilíbrio entre o tempo dedicado ao trabalho, lazer e família. Espera-se que os resultados desse estudo contribuam a continuidade de estudos acerca da adição ao trabalho, fenômeno recente e ainda pouco estudado, de forma a desenvolver estratégias de prevenção, promoção e intervenção, tanto individuais quanto organizacionais

Palavras-chave: Adição ao trabalho. Workaholic. Engajamento profissional. Gestão de pessoas. Construção civil.

\section{ABSTRACT}

The requirements addressed to managers are a consequence of working world's transformation, which can lead to an increase in working hours and maximum tax and mental involvement. The objective of this study is to evaluate the trend of the profile of a construction company's managers, considering the behaviors of engagement and addition to the work. The method used was descriptive, with a qualitative approach. Data were collected through semistructured interviews with six administrative managers and they were analyzed using the content analysis technique. The results showed that the managers present a tendency to overwork, extension of the workload and an imbalance among the time spent working, leisure and family. It is hoped that the results of this study will contribute to the continuity of studies of this recent phenomenon and little studied so far, in order to develop strategies of prevention, promotion and intervention, both individual and organizational.

Keywords: Workaholism. Workaholic. Professional engagement. Professional engagement. Personnel management. Building constructions.

Data de submissão: 10 de fevereiro de 2017.

Data de aprovação: 2 de novembro de 2017. 


\section{INTRODUÇÃO}

O âmbito da construção civil compreende empresas de diversos portes e divide-se nos subsetores de materiais de construção, construção pesada e edificações. A indústria da construção civil tem relação muito importante com a infraestrutura e a qualidade de vida da população brasileira e também com o desenvolvimento econômico e social do país (MONTEIRO FILHA; COSTA; ROCHA, 2010).

No entanto, no Brasil, as organizações da construção civil ainda são conhecidas pelo retrocesso de procedimentos gerenciais e técnicas construtivas devido à mão de obra desqualificada, baixos índices de produtividade, atrasos nos prazos de entrega, não conformidade e baixa qualidade do produto final. Essa realidade explica a preocupação de construtoras com seus sistemas de gestão e com a qualificação gerencial (FREJ; ALENCAR, 2010).

Nesse contexto, as exigências dirigidas aos gestores são consequência da transformação do mundo do trabalho, podendo levar ao aumento da jornada laboral e ao máximo envolvimento físco e mental com o trabalho e com a empresa. Absorver-se de maneira exagerada pelo trabalho, manter o ritmo rápido e buscar de forma desmedida resultados podem ser indícios de trabalhadores viciados em trabalho, derivando o fenômeno workaholic (FERREIRA, 2003).

O workaholism ou Adição ao Trabalho (AT) tem mostrado expressivo crescimento no atual contexto laboral (HEWLETT; LUCE, 2006). O comportamento do adicto em trabalho é socialmente aceitável (GRIFFITHS, 2011), sendo que algumas culturas organizacionais estimulam e privilegiam condutas que ultrapassam o contrato funcional de trabalho, os horários oficiais estabelecidos, sem preocupar-se com os efeitos dessa conduta no âmbito pessoal e familiar do trabalhador (MORENO-JIMÉNEZ et al., 2005). Esse fenômeno é reflexo de uma economia globalizada e um mercado cada vez mais competitivo, exigindo que os trabalhadores produzam mais e de forma mais rápida. Aliado a isso, há o desejo de manter um estilo de vida estável aliado ao declínio real de salários, resultando na necessidade de trabalhar ainda mais (PORTER; KAKABADSE, 2006).

A AT, no entanto, repercute negativamente na vida do trabalhador, pois há uma redução no desempenho (SHIMAZU; SCHAUFELI, 2009), dificuldades em se desligar e insatisfação com a carreira (SUSSMAN, 2012). Em relação à saúde, sintomas somáticos, estresse, distúrbios do sono, ganho de peso, ansiedade, hipertensão e problemas cardiovasculares, depressão e síndrome de burnout (LíBANO et al., 2010; SUSSMAN, 2012).

Por outro lado, essa transformação do mundo do trabalho também pode apontar gestores engajados, que comumente vão mais à frente do esperado na sua rotina de trabalho, oportunizando sucesso aos outros e à organização. Os líderes são os maiores facilitadores do engajamento, todavia, também precisam estar engajados. Comumente, estão dispostos a atuar com grande desempenho para alcançar os resultados organizacionais. O engajamento também representa a identificação das pessoas com os objetivos, estratégias, missão, visão, cultura e valores da organização (BEM, 2013), porém de maneira mais sadia se comparado ao comportamento workaholic. Trata-se de um estado mental positivo relacionado ao trabalho com altos níveis de energia, entusiasmo e dedicação refere um profissional engajado no trabalho (SCHAUFELI; TARIS; VAN RHENEN, 2008). 
Dessa forma, o objetivo geral desta pesquisa é avaliar a tendência de perfil dos gestores de uma empresa de construção civil, considerando os comportamentos de engajamento e adição ao trabalho. A pesquisa é de abordagem qualitativa e foi utilizado um roteiro de entrevista para a coleta de dados, cujas perguntas foram elaboradas com base nas teorias apresentadas. Optou-se por investigar gestores, pois há indícios de o fenômeno workaholic ser recorrente em gestores (ZARATINI; PADILHA, 2010; MARINA et al., 2014; MÄKIKANGAS et al., 2015; MATSUDAIRA et al., 2013), porém são escassos os estudos com abordagem qualitativa (PINHEIRO, 2016).

O tema ora apresentado é relevante devido ser este um novo modelo de comportamento nas organizações, merecendo ser conhecido tanto por gestores que estão preocupadas com a saúde dos seus trabalhadores, quanto por funcionários dos quais estão sendo exigidos ritmo e produtividade elevada. Portanto, os resultados deste estudo poderão ser utilizados pelas organizações e respectivas áreas de Recursos Humanos no desenvolvimento de políticas de prevenção e promoção da saúde do trabalhador.

\section{FUNDAMENTAÇÃO TEÓRICA}

A década de 1990, quando a globalização exerceu seus efeitos sobre todo o mundo, representa o período das mais rápidas transformações econômicas, tecnológicas e sociais já ocorridas na história. Desde então, o trabalho foi colocado como uma categoria central no âmbito de preocupações, visto que a competitividade, estabelecida sem fronteiras, requer produtividade com qualidade, tornando-se indispensáveis trabalhadores qualificados (GOULART, 2010). O trabalho possui um valor positivo na sociedade atual, no entanto, quando se torna excessivamente valorizado, pode gerar consequências negativas sendo a Adição ao Trabalho uma delas (LíBANO et al., 2010). Dessa forma, é importante contextualizar como vem se construindo a relação do indivíduo com o trabalho e com a organização, bem como compreender aproximações e diferenças relacionadas aos conceitos de comprometimento, engajamento e adição ao trabalho, conceitos que norteiam esse estudo.

Importante destacar que busca sistemática da literatura nacional e internacional realizada por Pinheiro (2016) revelou escassez de estudos quando comparado com outras formas de adoecimento no trabalho. A autora coloca que, no Brasil, nas principais bases de dados nacionais (Scielo e Pepsic), apenas três estudos foram encontrados sobre a AT. Dois destes estudos são de abordagem quantitativa e um, trata da tradução e adaptação de instrumento.

\section{A relação do indivíduo com o trabalho e a organização}

O trabalho vem sendo amplamente pesquisado devido sua abrangência, centralidade e impacto na vida das pessoas, além de meio de sobrevivência (PEREIRA; TOLFO, 2017). É uma atividade produtiva que agrega valor a alguma coisa. É um processo que coloca as pessoas em ligação umas com as outras, ajudando o indivíduo a desenvolver e aperfeiçoar sua identidade. Um trabalho que tem sentido possibilita que as pessoas consigam utilizar suas capacidades e habilidades, tanto para seu local de trabalho como para a organização num modo geral (MORIN, 2001). Existem diversas características que dão sentido ao trabalho, como realizá-lo na forma de prazer e com sentimento de realização, ou o trabalho como disciplina do conhecimento, além do trabalho como forma de sobrevivência (KANAANE, 2009). 
Assim, o trabalho é constituinte do sujeito e central nos processos de subjetivação, sendo a organização dos modos laborais determinantes para as vivências de prazer e sofrimento. O sujeito pode, portanto, se defrontar com prescrições, procedimentos, materiais ou instrumentos a serem manipulados; ou colaborar com uma hierarquia organizacional e com colegas, com os quais é preciso interagir para atingir o objetivo de produção de um bem ou de um serviço (BENDASSOLI; SOBOLL, 2011).

De acordo com Antunes (2003), as pessoas gastam boa parte de suas horas diárias no trabalho, lhes possibilitando o sustento, contribuindo para a criação de uma identidade social, além do sentido de utilidade enquanto participante de um processo. O foco do trabalho tende a consistir na competência e em resultados, não levando em conta a maneira como esses resultados foram atingidos. Desse modo, complementa o autor, o trabalho foi se organizando em normas, concepções e regras contraditórias, dificultando uma incorporação resistente dos valores organizacionais.

Na sociedade capitalista, comumente o trabalho é concebido como sinônimo de emprego (ANTUNES, 2000). Rebello (2002) confere duas perspectivas relacionadas ao trabalho, em que o emprego pode ou não ser comparado: A primeira refere o trabalho vinculado a emprego denotando "a lógica do emprego assalariado", associado à existência de um posto de trabalho, que caracteriza o emprego dito tradicional, com o pagamento de contrapartida financeira - o salário, a dedicação em tempo integral (jornada de trabalho) e o contrato de trabalho por tempo indeterminado. A outra perspectiva contrapõe trabalho a emprego, caracterizada pela "lógica da atividade", que se refere a outras atividades com funções sociais e que conferem status ao seu realizador.

O envolvimento com o trabalho é o estágio de dedicação no qual os profissionais percebem que ele faz parte de suas vidas, pois investem seu tempo e sua energia se dedicando às suas tarefas diárias. Sendo assim, os funcionários que apresentam envolvimento com o trabalho têm maiores oportunidades de revelar necessidades de crescimento e de mostrar interesse na participação do processo de tomada de decisões. Esses trabalhadores dificilmente irão se atrasar ou se ausentar do seu trabalho, e geralmente estarão dispostos a trabalhar horas extras a fim de atingir um melhor nível de desempenho na organização (NEWSTROM, 2008).

Zanelli, Silva e Tolfo (2011) ressaltam que pessoas com alto nível de satisfação com o trabalho não possuem interesse em sair das empresas na qual trabalham. Também são as pessoas que têm pouca frequência de faltas e que apresentam um alto desempenho profissional e maior produtividade. Os funcionários, quando obtêm retorno de suas realizações de trabalho, começam a acreditar no potencial de satisfazer suas necessidades pessoais, familiares e profissionais. Os autores descrevem que os empregados almejam uma relação de troca justa com a empresa, buscando conseguir apoio para dificuldades que enfrentam em determinados momentos e reciprocidade organizacional.

Desse modo, os níveis de satisfação, envolvimento e comprometimento dos trabalhadores tendem a ter vínculo entre si, pois é esperado que as pessoas apresentem, ao mesmo tempo, esses indicadores na organização onde trabalham. Quando há envolvimento com o trabalho, o profissional também mantém fortalecido outros vínculos afetivos importantes, como o comprometimento e o engajamento, a satisfação com o trabalho, a chefia, o salário, os colegas e as promoções (ZANELLI, BORGES-ANDRADE; BASTOS, 2014). 


\section{Engajamento profissional}

As organizações e seus ambientes encontram-se em constantes mudanças. Novas tecnologias são criadas, concorrentes entram e saem do mercado, o que determina uma capacidade de transformação das organizações, que as obriga a se ajustarem aos mercados e às contínuas inovações que caracterizam a atual realidade. Com intenção de sobreviver nessas circunstâncias, as empresas precisam de seus funcionários e gestores unidos para alcançarem as estratégias organizacionais, sendo as pessoas o diferencial competitivo no mercado. É importante enfatizar que ter trabalhadores comprometidos e engajados diante da mudança é essencial para o processo de melhoria e desempenho nas empresas (PINTO, 2011).

Kanaane (2009) refere que as organizações possuem grande influência sobre os estados mentais e emocionais dos indivíduos que ela compõe, pois o ambiente de trabalho necessita estar associado a condições de qualidade de vida, que provoquem o bem-estar do funcionário e seu comprometimento. Caso contrário, podem gerar um clima de desmotivação e insatisfação na organização. O autor complementa que "o engajamento do homem ao trabalho dá-se a partir do momento em que ele percebe que o que ele busca o que quer e o que precisa poderá ser atendido" (KANAANE, 2009, p. 86).

$O$ processo de engajamento engloba o avanço de recursos de gestão de pessoas adaptadas à realidade da organização e das diferentes equipes que a compõem. Para que as empresas atraiam, retenham e mantenham seus profissionais comprometidos, é necessário oferecer uma proposta de valor para atraí-los, reger os talentos para que contribuam na sua carreira e ter compreensão de que as pessoas são as peças chave da organização, pois são as que agregam inteligência ao negócio (LINS; SOTTOVIA, 2011).

Os funcionários engajados trabalham e pensam de forma proativa, são concentrados nos objetivos que pretendem atingir e consistentes com o que é bom para a organização. Eles são profissionais persistentes, mesmo quando o trabalho não está seguindo de acordo com o planejado (MACEY et al., 2011). Os autores acrescentam que existem quatro importantes componentes para os funcionários se sentirem engajados na empresa: a) sentimentos de urgência: é a energia e a determinação apontadas aos objetivos; b) sentimentos de estar focado: concentração no trabalho; c) sentimentos de intensidade: profundidade da concentração; d) sentimentos de entusiasmo: estado emocional.

Carmello (2013) refere que há certa intersecção entre o conceito de comprometimento e o engajamento. $\mathrm{O}$ comprometimento está associado a pessoas que estão conscientes de seus compromissos funcionais e que cumprem com seus deveres e responsabilidades, realizando apenas as tarefas que thes foram propostas em sua contratação. Já o engajamento está relacionado a pessoas comprometidas funcionalmente e emocionalmente, que cumprem suas atividades e estão sempre dispostas a fazer algo a mais pela empresa. Acrescenta o autor que os engajados acreditam e apoiam o sucesso da empresa e sentem orgulho em fazer parte da organização na qual trabalham.

Bakker e Demerouti (2008) lançaram a expressão "engajamento no trabalho" e a relacionaram a um estado mental caracterizado por três elementos fundamentais: o vigor, que sugere altos níveis de energia e resiliência mental no trabalho; a dedicação, que se refere a estar-se profundamente envolvido no trabalho, experimentando uma forte sensação de significado, entusiasmo e desafio; e a absorção, que indica alto nível de concentração, sendo que o tempo passa rapidamente no ambiente de trabalho.

Trabalhadores engajados são indivíduos que se encontram fisicamente, cognitivamente e emocionalmente vinculados com seus papéis de trabalho (BAKKER, 2011). O engajamento pode ser um 
indicador de bem-estar e qualidade de vida, bem como o papel do gestor enquanto promotor desse sentimento na sua equipe de trabalho.

\section{Adição ao trabalho}

Nos dias atuais, o ser humano necessita estar em constante aprendizagem para conseguir ter sucesso e se manter na organização em que trabalha. As expectativas do indivíduo em relação ao trabalho precisam corresponder aos objetivos e aos valores adotados pela empresa, visando à sincronia entre as partes, com o objetivo de alcançar resultados satisfatórios. As pessoas tendem a trabalhar excessivamente para atingir as metas planejadas pela empresa e conquistar o sucesso profissional, porém, às vezes, fazem do trabalho o seu principal motivo de viver, revelando um novo fenômeno de comportamento nas organizações, definido como workaholic ou adição ao trabalho. Trata-se de uma expressão americana que teve origem na palavra "alcoólatra" e serve para denominar um indivíduo viciado, não em álcool, mas em trabalho (STEFANICZEN; STEFANO; MACHADO, 2010).

Serva e Ferreira (2006) afirmam que o psicólogo americano Wayne Oates, em 1968, no artigo "Onbeinga 'workaholic", foi o primeiro a relatar seu próprio comportamento semelhante a um alcoólatra. O autor assegurava também ser um viciado, mas em trabalho. Em 1971, Oates (p. 10) referiu o termo workaholic como descrição daquela "pessoa cuja necessidade de trabalho tornou-se tão excessiva que cria perturbação perceptível ou interferência com a sua saúde física, felicidade pessoal e relações interpessoais, e com o seu bom funcionamento social".

Desta forma, workaholism foi definido como um vício para trabalhar, compulsão ou a necessidade incontrolável para trabalhar constantemente. Ficar absorvido de forma intensa com o trabalho, com longas jornadas diárias, carga horária de trabalho exagerado, ritmo acelerado de se trabalhar e busca desregrada de resultados são características da adição ao trabalho (SERVA; FERREIRA, 2006).

A AT é conceituada como uma experiência subjetiva na qual ocorre uma evidente perda de controle, em que o trabalhador continua a se envolver no trabalho mesmo sabendo das consequências (ANDREASSEN, 2013). O investimento é excessivo e não é motivado por questões financeiras (RANTANEN et al., 2015; GRIFFITHS, 2011; RESTREPO, 2011; SHIMAZU; SCHAUFELI, 2009).

Pesquisas sobre adição ao trabalho acenam para as profissões como gestores (MARINA et al.,2014; MÄKIKANGAS et al., 2015; MATSUDAIRA et al., 2013), sendo que índices mais expressivos de AT são percebidos em gestores, empresários e executivos (LITTMAN-OVADIA; BALDUCCI; BEN-MOSHE , 2014), e o setor da construção também registra altos índices (TARIS; VAN BEEK; SCHAUFELI, 2012). Restrepo (2011), em suas pesquisas, indica algumas características profissionais que podem vincular a AT, o trabalho como estado de espírito, um misticismo e religiosidade, dedicação exclusiva para com suas práticas laborais, tendendo a sacrificar seu tempo livre, o que com o tempo leva ao isolamento social.

A AT é, portanto, caracterizada pela dependência de trabalho. O sujeito trabalha de maneira exagerada e mesmo reconhecendo o exagero ele não consegue se controlar ou reduzir a sua carga de trabalho. Serva e Ferreira (2006) complementam que esses profissionais apresentam necessidade de estarem no controle, possuem uma preocupação acentuada com detalhes e forte identidade com a carreira, motivação de realização. Os indivíduos com padrões de comportamento de adição são pessoas que gastam boa parte de seu tempo em atividades de trabalho, ao invés de curtir períodos com família, amigos e lazer. 
Eles insistem em pensar repetidamente em assuntos relacionados ao trabalho, mesmo quando não estão efetivamente trabalhando; trabalham muito além do que é admissível em uma carga horária trabalhista (RANTANEN et al., 2015; SERVA; FERREIRA, 2006).

$\mathrm{O}$ que pode diferenciar um indivíduo adicto de um profissional dedicado ao trabalho é de que o primeiro é viciado em trabalho, possui um desejo obsessivo por trabalhar, ligado à falta de controle sobre as horas dedicadas ao mesmo. A dedicação exagerada apresenta-se desnecessária diante das necessidades econômicas do indivíduo e o que é determinado pela organização onde trabalha (RANTANEN et al., 2014; GRIFFITHS, 2011; RESTREPO, 2011; SHIMAZU; SCHAUFELI, 2009; SERVA; FERREIRA, 2006).

Revisão de publicações e leitura crítica-reflexiva sobre a adição ao trabalho realizada por Garrido Piosa (2014) revelou que é difícil diferenciar a dedicação ao trabalho da AT por quatro razões fundamentais: a não aceitação do problema pelo dependente ao trabalho; pessoas muito trabalhadoras são admiradas na sociedade, sendo a dedicação excessiva considerada como uma qualidade; a falta de informação para a população para a consciência da adição ao trabalho como doença; a não contemplação da adição ao trabalho dentro dos manuais de critérios de diagnóstico (CID-10).

\section{PROCEDIMENTOS METODOLÓGICOS}

Trata-se de um estudo descritivo, com abordagem qualitativa. $O$ enfoque qualitativo busca principalmente a dispersão ou expansão dos dados e das informações, e a reflexão é a ponte que une o pesquisador e os participantes (SAMPIERI; COLADO; LUCIO, 2006).

Participaram, do estudo, seis gestores de uma empresa do ramo de construção civil do interior do Rio Grande do Sul (RS), selecionados por acessibilidade e conveniência. Considerou-se o critério de saturação teórica, em que o fechamento amostral é definido quando as unidades que vão sendo adicionadas não fornecem dados novos, ocorre certa redundância ou repetição, não sendo considerado relevante persistir a coleta de dados (FONTANELLA; RICAS; TURATO, 2008).

Em relação ao perfil dos respondentes, dos seis gestores administrativos, três são do sexo feminino e três, do sexo masculino e a faixa etária dos entrevistados variou de 33 a 57 anos de idade. Além disso, os sujeitos da pesquisa são gestores administrativos, que atuam em área financeira, contábil, recursos humanos, informática e controladoria. Todos possuem graduação, sendo que a maioria tem pós-graduação ou estava prestes a concluir especialização.

Para a coleta de dados, optou-se pela entrevista, que foi realizada face a face, com o auxílio de um gravador para a maior fidelidade do material obtido, em lugar privativo para o maior conforto e segurança dos participantes. No método semiestruturado, o entrevistador deve seguir o roteiro, porém, muito parecido ao de uma conversa informal, podendo haver discussão quando se julgar necessário (BONI; QUARESMA, 2005). Essa técnica permite, ainda, que o entrevistado exponha sua opinião sobre o tema proposto, o que faz com que seja possível descobrir elementos importantes para o estudo. Antes de realizar as entrevistas, foi apresentado o tema do estudo e seus objetivos, e também foi garantido o sigilo das informações fornecidas. Os dados das entrevistas foram transcritos na íntegra.

Para a interpretação dos dados, foi escolhida a técnica de análise de conteúdo que, segundo Caregnato e Mutti (2006), é constituída por três etapas: a pré-análise; a exploração do material e o tratamento dos resultados e interpretação. Trabalha-se com os aspectos individuais e atuais da linguagem por meio das 
condições empíricas do texto, que é um meio de expressão do indivíduo, no qual o entrevistador busca classificar as palavras ou frases que se repetem, compreendendo uma expressão que as representem.

Os dados foram organizados por categorias apriorísticas, que se remete a quando o pesquisador possui previamente, segundo interesse, categorias predefinidas (CAMPOS, 2004). A ideia central da categorização consiste em identificar essas categorias, as relações existentes entre os dados levantados, procurando compreender os resultados a partir da interpretação e relação com a teoria (APOLINÁRIO, 2006).

\section{RESULTADOS E DISCUSSÃO}

O conteúdo a seguir foi dividido nas categorias: Significado do trabalho e Grau de dedicação ao trabalho.

Categoria 1: Significado do trabalho

Ao analisar as respostas dos entrevistados quanto ao significado do trabalho em suas vidas, foram identificados fatores ligados à importância da escolha de um trabalho com o qual possuem afinidade, de modo que isso leva à satisfação e à motivação. Os gestores E2, E3 e E6 expressam respectivamente:

[...] escolhi a profissão que eu realmente entendo e gosto de fazer. Essa motivação, por ter essa consciência da escolha acertada de tu poder ver o resultado do teu trabalho, isso te motiva muito mais para vir trabalhar (E2).

Eu entendo que se tu trabalhar sem motivação significa tu dizer que não gosta do que tu faz. Então motivação faz parte do meu dia-a-dia, eu venho motivado, e mesmo no final do dia quando encerro atividade eu tento me manter motivado para o dia seguinte retomar e continuar trabalhando nesse mesmo ritmo (E3).

[...] É uma coisa que eu gosto muito de fazer e me identifico bastante. Me sinto motivada pela valorização profissional, não tenho nada a me queixar (E6).

A satisfação no trabalho pode estar associada a sentimentos positivos para com o emprego, ambientes onde os funcionários possam demonstrar suas competências e assim melhorar seu desempenho, sua produtividade e com isso seu interesse para com suas práticas laborais (ROBBINS, 2005). Percebe-se, nas falas dos participantes, que o sentimento de satisfação existe no seu contexto de trabalho, demonstrando identificação e apreço e com isso realização através dos resultados que atingem. A satisfação tem uma relação positiva com o desempenho individual (JUDGE et al., 2001).

O trabalho tem a capacidade de influência significativa sobre a satisfação e motivação, representando um valor muito importante para o bem-estar do trabalhador (WOOD JR., 2005). Também pode ser entendido como um fator fundamental para a vida das pessoas e constitui-se como um dos pilares para a estabilidade da família e da sociedade. Ainda, Nobre (2011) salienta que os aspectos motivacionais são os mesmos que conduzem a pessoa a determinado destino e objetivo, os quais são específicos a cada um.

Entende-se que, quando os indivíduos extraem satisfação em demasia na realização do trabalho, pode-se identificar o perfil adicto, que, segundo Gomes e Soares (2011), são aqueles compulsivos pelo trabalho e que designam horas extras e tempo livre pessoal a trabalhar. Em síntese, são indivíduos cujos sentimentos, comportamentos e pensamentos, são vigorosamente comandados pelo seu trabalho, o que não foi observado nas falas. 
Também foram mencionadas questões voltadas à importância de ver os resultados do trabalho, a influência como gestor de pessoas, o relacionamento entre os funcionários e a variedade das atividades, conforme falas dos entrevistados E1, E2 e E3:

O relacionamento com as pessoas, de procurar identificar o que ela pode agregar no meu grupo de trabalho e procurar identificar o potencial dela para o meu setor dar resultado, pra mim é instigante, pois lidar com pessoas é fascinante [...] Essa rotina de tu te relacionar, de tu fazer com que as pessoas se harmonizem dentro de um ambiente de trabalho em prol de um objetivo é como se tu fosse um maestro de uma orquestra e tu tivesse que fazer a orquestra tocar uma sinfonia (E1).

Pra mim é a questão da realização profissional, é de ver os resultados, é de acompanhar os desenvolvimentos das pessoas, de conseguir formar profissionais, de conseguir conduzir eles a também uma busca de objetivos, de conseguir alinhar isso também com o resultado da empresa (E2).

[...] sempre fico atento a distribuição de tarefas, ter o equilíbrio de tarefas na equipe pra não sobrecarregar ninguém, e não deixar de ter a visão de um todo, mesmo sendo uma empresa departamentalizada, o gestor tem que ter a visão do todo (E3).

Os relatos expressam que o líder tem um compromisso de formar pessoas e também de buscar um ambiente no qual o funcionário se sinta à vontade. Silva, Peixoto e Batista (2011) mencionam que as organizações precisam de líderes competentes para trabalhar e ajudar a solucionar os problemas em grupo, preparados para trabalhar em equipe e também compreender a importante habilidade de transmitir conhecimento, saber delegar tarefas e oferecer oportunidades. Ao contrário, gestores com tendência à adição ao trabalho, demonstram baixo nível de empoderamento das equipes, dada a autonomia reduzida que os funcionários dispõem, resultado do comportamento centralizador do líder (ZARATINI; PADILHA, 2010).

Neste sentido, E3 e E5 complementam:

Ser gestor tu tem que saber que vai ter desafios, tu vai ter que delegar, tem que cobrar, pois isso faz parte, e tem que saber trabalhar com isso. Tem que saber cobrar, mas sem pisar nessa pessoa, sem magoar. [...] Eu vejo que a empresa que eu trabalho sempre valorizou meu trabalho, e as etapas de crescimento dentro da empresa sempre foram muito desafiadoras [...] há oportunidade que a gente tem de desenvolver o trabalho, maneira de como são contratadas as pessoas, que resultam pelo menos a minha equipe sempre vejo um bom ambiente de trabalho, as pessoas se respeitam (E3).

[...] eu me considero aqueles gestores que passa todo o tipo de informação, não pretendo ficar com ela, até porque acho que não tenho idade e nem pretensão de ficar com algum conhecimento e não poder transmitir. Essa é uma mudança que a gente vai aprendendo na vida profissional, vai caminhando, delegando aprendendo a fazer, passando a tarefa e o conhecimento de como fazer, você também pode desenvolver e crescer profissionalmente (E5).

A liderança tem o papel de desenvolver funcionários capazes, deve ter um interesse genuíno nas pessoas e no resultado da empresa. São pessoas que inovam, criam e têm o conhecimento para desenvolver o trabalho (BENEVIDES et al., 2015). Em vista disso, é comum profissionais que têm cargos de liderança fazerem com que o trabalho consuma o seu tempo pessoal, sendo aceito pensar nos compromissos laborais mesmo no tempo livre (GASPAR; PORTÁSIO, 2009).

Outro fator que contribui para o aumento da carga horária da liderança é o fato de que as expectativas das pessoas têm aumentado, tanto com relação às exigências individuais, quanto laborais e de ambiente. 
Muitas pessoas esperam que a empresa adote políticas de equilíbrio trabalho-família, práticas ambientais, patrocine conhecimento e novas experiências, inclusive internacionais, aumentando assim a exigência para com a liderança (BENEVIDES et. al, 2015).

Categoria 2: Grau de dedicação ao trabalho

Em relação ao espaço que o trabalho ocupa na vida dos entrevistados, E1, E3 e E5 relatam:

[...] a maior parte do tempo da minha vida é aqui dentro, então é natural que esse tempo eu trabalho me dedico ao trabalho, se tu comparar horas semanais né! Pois a maior parte do tempo tu trabalha dentro da empresa, [...] mas a maior parte do tempo eu estou envolvido com o trabalho (E1).

[...] o trabalho é realmente o que mais eu me dedico atualmente, porém tento não me exceder [...] já tive experiências de bem no início da minha carreira de ter falhado nisso, de tocar, tocar, e prejudicar o relacionamento, hoje eu não faço mais, e recomendo que ninguém faça [...] o trabalho é fundamental e essencial, mas não é tudo, tem que saber equilibrar (E3).

[...] a minha vida, ela basicamente sempre foi muito mais no trabalho do que outra ocupação [...] eu tenho sempre uma grande preocupação com o trabalho, em tentar pensar o amanhã e o futuro, porque a gente pensando no passado eu não consigo render muito, pensando no presente e no futuro eu acredito que a gente tem que se preocupar sim [...] (E5).

É possível perceber que os gestores entrevistados ocupam várias horas da sua vida com suas práticas laborais. De acordo com Schaufeli, Taris e Bakker (2008), os motivos que levam as pessoas a trabalharem muitas horas podem estar relacionados a problemas financeiros, relacionamentos conjugais ou familiares empobrecidos, forte interesse em ascender profissionalmente, sem que necessariamente sejam adictos ao trabalho.

Outro fator que pode influenciar a alta dedicação ao trabalho diz respeito ao comportamento de engajamento, que está relacionado à energia e a percepção de um indivíduo, no qual é visível para os outros, a demonstração de iniciativa pessoal, adaptabilidade, esforço e empenho direcionados a atingir os objetivos da empresa (MACEY et al., 2011). Para os funcionários comprometidos e engajados, o trabalho é sinônimo de prazer, onde há envoltura, dedicação e bem-estar. São formas saudáveis de se relacionar com o trabalho, caracterizados por uma forte energia e uma identificação para com suas atividades laborais (BAKKER; LEITER, 2010).

Importante salientar que, o que diferencia profissionais que possuem relação sadia com o seu trabalho e os adictos, é o desejo obsessivo com evidente falta de controle sobre o trabalho e as horas dedicadas a ele. Desta forma, não se trata de trabalhar muito, mas de trabalhar além do solicitado (SERVA; FERREIRA, 2006).

Os entrevistados E3, E4 e E5 manifestam, no entanto, a linha tênue existente entre a relação sadia e patológica com o trabalho, uma vez que referem o quanto o excesso do trabalho acabou por afetar sua saúde:

[...] é aquela ânsia de querer abraçar tudo. Hoje eu sei dizer que não é salutar, em primeiro lugar para a pessoa... Não é salutar para o meio que ela vive porque ela vai acabar falando só de trabalho, tu não tem outro assunto, só trabalho, trabalho, e para empresa porque essa pessoa pode estar inibindo outras pessoas de crescerem profissionalmente (E3). 
[...] um pouco eu percebi, porque tava me afetando, causando inclusive o meu estado físico, tinha bastante dor de estômago, eu tava começando a dormir mal, e um pouco o meu marido, que começou a me alerta [...] Então, não é o que eu quero pra mim, acho que o trabalho não é vida da gente, é uma parte da vida da gente. E eu tava fazendo com que o trabalho se tornasse a minha vida, eu não quero isso pra mim (E4).

Várias vezes, esse é um aspecto extremamente negativo que por muitos anos, por trabalhar demais ou horários demais me afeto muito em várias ocasiões. Hoje não mais tanto, mas realmente me atingiu muitas vezes, a tal ponto de trabalhar até no hospital [...] (E5).

As falas parecem vir, portanto, ao encontro do que colocam Camelo e Angerami (2008), que a sobrecarga de trabalho, a falta de domínio sobre as atividades funcionais e a tensão podem causar estresse. Pode-se considerar que a carga de trabalho é consequência de um conjunto de variáveis que decorre de cada indivíduo e das condições em que é desempenhada a atividade, conforme relata E5: "O meu trabalho já atingiu muito do meu tempo livre, desisti de viagens por causa do trabalho, já não tirei férias por causa do trabalho, fiz tudo isso". Os autores complementam que o exagero de horas trabalhadas diminui a oportunidade de apoio social ao sujeito, ocasionando insatisfação, estresse e demais problemas de saúde.

Assim, observa-se que existem vários aspectos que podem levar um gestor a se tornar um viciado ao trabalho. O estresse é uma das doenças que se relacionam ao perfil de workaholic. A adição ao trabalho não ocorre de uma hora para a outra, o sujeito só percebe que está adoecido quando a saúde já está prejudicada e os conflitos familiares são eminentes. O desejo de o indivíduo se tornar um executivo de sucesso e seu envolvimento excepcional com o trabalho faze com que o próprio ultrapasse muitos de seus valores, sem mesmo ter tempo de preocupar-se com assuntos de saúde e sua família. Infelizmente, o equilíbrio da vida pessoal e o trabalho representam-se, até então, distantes da realidade empresarial (OLIVER et al., 2004).

Os resultados da pesquisa sugerem o quão importante são, as práticas organizacionais saudáveis, buscando diminuir as chances de ocorrência da AT nestes profissionais. Atualmente o mundo corporativo tem patrocinado o trabalho excessivo, sendo inclusive motivo de premiação, por desempenho ou atingimento de metas, cada vez mais audaciosas. Também é importante ressaltar, conforme resultados do estudo, a consciência dos gestores em relação a esse comportamento, percebendo e buscando as mudanças necessárias para um trabalho mais equilibrado.

\section{CONSIDERAÇÕES FINAIS}

Esse estudo teve como objetivo avaliar a tendência de perfil dos gestores de uma empresa de construção civil, considerando os comportamentos de engajamento e adição ao trabalho, utilizando-se a abordagem qualitativa. Definiu-se esse público-alvo, pois há indícios de o fenômeno workaholic ser recorrente em gestores (ZARATINI; PADILHA, 2010; MARINA et al., 2014; MÄKIKANGAS et al., 2015; MATSUDAIRA et al., 2013), porém são escassos os estudos com essa abordagem (PINHEIRO, 2016).

De um modo geral, os resultados indicaram tendência ao trabalho excessivo, extensão da carga horária laboral e desequilíbrio entre os tempos dedicados ao trabalho, família e lazer. No entanto, não há evidências significativas quanto a um perfil workaholic.

Os entrevistados afirmam que o trabalho tem grande importância nas suas vidas e há engajamento 
em suas tarefas. Declaram estarem satisfeitos e motivados com as atividades que desempenham, e que isso pode estar relacionado com sua escolha de carreira e os objetivos pessoais que possuem. Ainda ressaltaram que, primeiramente, é necessário estar motivado pessoalmente para consequentemente transmitir isso para a sua equipe, porque é através das pessoas que se chega aos resultados esperados pela empresa.

Observou-se que apenas um dos gestores demonstra ser viciado em trabalho e tem ciência da sua adição, pois tem conhecimento de que trabalha em demasia e não consegue se desligar do trabalho mesmo estando fora da empresa. Além disso, reconhece que já sofreu conflitos no meio familiar e percebeu o quanto isso afetou sua saúde. Como aponta Garrido Piosa (2014), é difícil diferenciar a dedicação ao trabalho da adição ao trabalho, pois pessoas muito trabalhadoras são admiradas na sociedade, sendo a dedicação excessiva considerada como uma qualidade e há a falta de informação para a população para a consciência da adição ao trabalho como doença.

Um dos gestores percebeu, em momento oportuno, o excesso de tempo dedicado ao trabalho, conseguindo mudar atitudes e hábitos. Em relação aos demais entrevistados, pode-se inferir que são considerados engajados e não viciados, pois tendem a organizar-se dentro das expectativas da empresa e seus limites de vida social, familiar e lazer. Ainda, manifestam emoções de bem estar, gozam de uma boa saúde, são capazes de transmitir sua energia positiva para seus colegas se espelharem em desempenhar suas funções com o máximo de engajamento.

Apontam-se, como elementos limitantes para esse estudo, a desejabilidade social, fator que pode ter contribuído em um viés nas respostas dos participantes. Ainda, os resultados encontrados possam decorrer do denominado "efeito do trabalhador sadio", que se refere a somente trabalhadores em boas condições de saúde participarem da pesquisa, uma vez que aqueles sob o efeito do fenômeno estudado estariam afastados do trabalho.

Aprofundar o conhecimento sobre a adição ao trabalho a partir da experiência e do saber dos trabalhadores em relação ao trabalho, seu sentido e suas repercussões, é indispensável para refletir alternativas eficazes de prevenção e promoção da saúde. Por fim, cabe destacar que o estudo de outras categorias pode subsidiar ações de estímulo à relação sadia entre empresa e funcionário, caracterizadas pelo perfil de engajamento, proporcionando qualidade de vida aos trabalhadores e maior produtividade.

\section{REFERÊNCIAS}

ANDREASSEN, Cecilie Schou. Workaholism: An overview and current status of the research. Journal of Behavioral Addictions, v. 3, n. 1, p. 1-11, 2013. Disponível em:

http://www.recoveryonpurpose.com/upload/Workaholism $\% 20 \mathrm{An} \% 20$ Overview\%20and\%20Current $\% 20$ Status $\% 20$ of $\% 20 \mathrm{t}$ he\%20Research.pdf. Acesso em 04 abr. 2017.

ANTUNES, R. Os sentidos do trabalho: ensaio sobre a afirmação e a negação do trabalho. 2. ed. São Paulo: Bontempo, 2000.

ANTUNES, Ricardo. Adeus ao trabalho? Ensaios sobre as metamorfoses e a centralidade do mundo do trabalho 9. ed.Campinas, São Paulo: Cortez, 2003.

APOLINÁRIO, Fábio. Introdução à análise quantitativa de dados. Metodologia científica-filosofia e prática da pesquisa. São Paulo: Thomson Leaming, p. 145-168, 2006.

BAKKER, Arnold B.; DEMEROUTI, Evangelia. Towards a model of work engagement. Career development international, v. 13, n. 3, p. 209-223, 2008. Disponível em

http://s3.amazonaws.com/academia.edu.documents/5210574/article_arnold bakker_164.pdf?AWSAccessKeyld=AKIAI WOWYYGZ2Y53UL3A\&Expires=1499688529\&Signature=3kiwQ7THgtM2m\%2BBuĀG68XhXKZT4\%3D\&responsecontent-disposition=inline\%3B\%20filename\%3DTowards_a_model_of_work_engagement.pdf. Acesso em 16 mar. 2017. 
BAKKER, Arnold B.; LEITER, Michael P. Where to go from here: Integration and future research on work engagement. Work engagement: A handbook of essential theory and research, p. 181-196, 2010. Disponível em https://books.google.com.br/books?hl=pt-

$B R \& \mid r=\& i d=k V 54 A g A A Q B A J \& o i=f n d \& p g=P T 381 \& d q=W h e r e+t o+g o+f r o m+h e r e:+$ Integration+and+future+research+on+w ork+engagement\&ots=J_Kwf6QiL8\&sig=aZJ-

FPzaqPKEBzWV1zKXSZqMiSw\#v=onepage\&q=Where\%20to\%20go\%20from\%20here\%3A\%20Integration\%20and\%20f uture\%20research\%20on\%20work\%20engagement\&f=false Acesso em 14 abr. 2017.

BAKKER, Arnold B. An evidence-based model of work engagement. Current Directions in Psychological Science, v. 20, n. 4, p. 265-269, 2011. Disponível em http://www.engagementfch.cl/wp-

content/uploads/2016/04/Bakker_2011_An_Evidence-Based_Model_of_Work_Engagement.pdf. Acesso em 08 jul. 2017.

BEM, Júlio César de. O engajamento e o processo de relacionamento interno mediado pela comunicação nas organizações. Porto Alegre, RS, 2013. Disponível em:

<http://repositorio.pucrs.br:8080/dspace/bitstream/10923/5489/1/000451399-Texto\%2bCompleto-0.pdf>. Acesso em: 14 set. 2015.

BENDASSOLI, Pedro F.; SOBOLL, Lis Andrea P. (Orgs.). Clínicas do trabalho: novas perspectivas para compreensão do trabalho na atualidade. São Paulo: Editora Atlas, 2011.

BENEVIDES, Nígila Maria da Costa et al. O estilo de liderança e os fatores motivacionais: um estudo na empresa Maré Mansa Eletros em Pau dos Ferros-RN. Informativo Técnico do Semiárido, v. 9, n. 2, p. 80-92, 2015. Disponível em: http://www.gvaa.org.br/revista/index.php/INTESA/article/view/4036. Acesso em: 15 abr. 2016

BONI, Valdete; QUARESMA, Sílvia Jurema. Aprendendo a entrevistar: como fazer entrevistas em ciências sociais. Santa Catarina, v. 2, n. 1(3), p. 68-80, jan./jul. 2005, Disponível em:

<https://periodicos.ufsc.br/index.php/emtese/article/view/18027/16976>. Acesso em: 10 set. 2015.

CAMELO, Silvia Helena Henriques, ANGERAMI, Emília Luigia Saporiti. Riscos psicossociais no trabalho que podem levar ao estresse: uma análise da literatura. Ciência Cuidado e Saúde,[S.I.], v. 7, n. 2, p. 232-240, abr./jun.2008. Disponível em: <http://ojs.uem.br/ojs/index.php/CiencCuidSaude/article/view/5010/3246>. Acesso em: 22 mar. 2016.

CAMPOS, Claudinei José Gomes. Método de análise de conteúdo: ferramenta para a análise de dados qualitativos no campo da saúde. Revista Brasileira de Enfermagem. v. 57, n. 5, p. 611-614, 2004.

CAREGNATO, Rita Catalina Aquino; MUTTI, Regina. Pesquisa qualitativa: análise de discurso versus análise de conteúdo. Texto Contexto Enferm,[S. I.], v. 15, n. 4, p. 679-84, 2006. Disponível em:

<http://www.scielo.br/pdf/tce/v15n4/v15n4a17>. Acesso em: 10 set. 2015.

CARMELLO, Eduardo. Gestão da singularidade. São Paulo: Gente, 2013.

FERREIRA, Joel Lincoln Oliveira. O Fenômeno Workaholic na gestão: Estudo de casos aplicados a gerentes. Curitiba, 2003. Dissertação (Mestrado em Administração). 2003, 200f. Centro de Pesquisa em Pós-Graduação em Administração, Universidade Federal do Paraná, Curitiba. Disponível em:

<http://dspace.c3sl.ufpr.br/dspace/bitstream/handle/1884/32770/R\%20-\%20D\%20-

\%20JOEL\%20LINCOLN\%20OLIVEIRA\%20FERREIRA.pdf?sequence=1\&isAllowed=y>.Acesso em: 6 ago. 2015.

FONTANELLA, B.J.B; RICAS, J.; TURATO, E.R. Amostragem por saturação em pesquisas qualitativas em saúde: contribuições teóricas. Cadernos de saúde pública, 2008. Disponível em: http://www.scielo.br/pdf/csp/v24n1/02. Acesso em 13 mar. 2017

FREJ, Tatiana Afonso; ALENCAR, Luciana Hazin. Fatores de sucesso no gerenciamento de múltiplos projetos na construção civil em Recife. Recife, PE: UFPE, 28 dez. 2010. Disponível em:

<http://www.scielo.br/pdf/prod/2010nahead/aop_200812127.pdf>. Acesso em: 13 set. 2015.

GARRIDO, P. M. (2014). Adicción al trabajo: características, detección y prevención desde una perspectiva integral. Revista electrónica semestral de enfermería, v. 13, n. 33, p. 362-369.

GASPAR, Denis Juliano; PORTÁSIO, Renato Mehler. Liderança e coaching: desenvolvendo pessoas, recriando organizações. Revista de Ciências Gerenciais, v. 13, n. 18, p. 17-41, 2009. Disponível em:

http://pgsskroton.com.br/seer/index.php/rcger/article/view/2601. Acesso em 14 abr. 2016.

GOMES, Jorge F. S.; SOARES, Patrícia. O excesso de trabalho mata ou dá prazer? Uma exploração dos antecedentes e consequentes do workaholismo. Psicologia, Lisboa: Ed. Colibri,v. XXV, n.1, p. 51-72, 2011. Disponível em: <http://www.scielo.mec.pt/pdf/psi/v25n1/v25n1a03.pdf>. Acesso em: 12 abr. 2016.

GOULART, Iris Barbosa (Org.) Psicologia organizacional e do trabalho: teoria, pesquisa e temas correlatos. 3. ed. São Paulo: Casa do Psicólogo, 2010.

GRIFFITHS, Mark. D. Workaholism: A 21st century addiction. The Psychologist: Bulletin of the British Psychological Society, v. 24, p. 740-744, 2011.

HEWLETT, Sylvia Ann; LUCE, Carolyn Buck. Extreme jobs: The dangerous allure of the 70-hour workweek. Harvard business review, v. 84, n. 12, p. 49-59, 2006. Disponível em http://imaginal-labs.com/wp-content/uploads/2013/10/Allureof-70-Hour-Workweek.pdf. Acessado em: 23 mai 2009. 
JUDGE, Timothy. A., et al. The job satisfaction- job performance relationship: A qualitative and quantitative review. Psychological Bulletin, v. 127, p. 376-407, 2001. Disponível em: http://panglossinc.com/JS-JP\%20published.pdf. Acesso em 23 mar. 2017.

KANAANE, Roberto. Comportamento humano nas organizações: O Homem Rumo ao Século XXI. 2. ed. São Paulo: Atlas, 2009.

PINHEIRO, Létícia Ribeiro Souto. Prevalência e preditores da adição ao trabalho em gestores. Tese (Doutorado em Psicologia). 2016, 39f. Programa de Pós-Graduação em Psicologia da Pontifícia Universidade Católica do Rio Grande do Sul, Porto Alegre. Disponível em http://tede2.pucrs.br/tede2/handle/tede/7129. Acesso em 13 jan. 2018

LÍBANO, Mario del et al. Validity of a brief workaholism scale. Psicothema, v. 22, n. 1, 2010. Disponível em: https://lirias.kuleuven.be/bitstream/123456789/486815/1/29.pdf. Acesso em: 09 jul. 2017

LINS, João; SOTTOVIA, Marco. Tendências em capital humano: Retenção de Talentos. PwC 14th Anual Global CEO Survey. 2011. Disponível em: <https://www.pwc.com.br/pt/estudos-pesquisas/assets/relat-retencao-talentos-11a.pdf>. Acesso em: 6 ago. 2015.

LITTMAN-OVADIA, Hadassah; BALDUCCI, Cristian; BEN-MOSHE, Tali. Psychometric properties of the Hebrew version of the Dutch Work Addiction Scale (DUWAS-10). The Journal of psychology, v. 148, n. 3, p. 327-346, 2014. Disponível em: http://www.wilmarschaufeli.nl/publications/Schaufeli/Test\%20Manuals/DUWAS_Hebrew.pdf. Acesso em 22 fev. 2017.

MACEY, William H.; SCHNEIDER, Benjamin; BARBERA, Karen M.; YOUNG, Scott A. Muito além do comprometimento: como montar equipes que farão sua empresa chegar ao topo. São Paulo: Gente, 2011.

MÄKIKANGAS, Anne et al. Engaged managers are not workaholics: Evidence from a longitudinal personcentered analysis. Revista de Psicología del Trabajo y de las Organizaciones, v. 29, n. 3, p. 135-143, 2013. Disponível em: https://lirias.kuleuven.be/bitstream/123456789/487510/1/100.pdf. Acesso em 23 fev. 2017.

MARINA, Romeo et al. Workaholism In Brazil: Measurement And Individual Differences. Adicciones, v. 26, n. $4,2014$. Disponível em: http://search.proquest.com/openview/0183911365e547959c0dccfbefcc544b/1?pqorigsite $=$ gscholar\&cbl=2032270. Acesso em 09 jul. 2017

MATSUDAIRA, Ko et al. Workaholism as a risk factor for depressive mood, disabling back pain, and sickness absence. PloS one, v. 8, n. 9, p. e75140, 2013. Disponível em: https://pdfs.semanticscholar.org/76f3/4d0c1bd0e7f64c5d1e26c26e53d91a8ae30d.pdf. Acesso em 16 fev. 2017.

MONTEIRO FILHA, Dulce Corrêa; COSTA, Ana Cristina Rodrigues da; ROCHA, Érico Rial Pinto da. Perspectivas e desafios para inovar na construção civil. BNDES Setorial, Rio de Janeiro, n. 31, p. 353-410, mar. 2010. Disponível em: <https://web.bndes.gov.br/bib/jspui/bitstream/1408/4522/1/BS\%2031_Perspectivas\%20e\%20desafios\%20para\%20inova r\%20na\%20constru\%C3\%A7\%C3\%A3o\%20civil_P.pdf>. Acesso em: 17 set. 2015.

MORENO-JIMÉNEZ, Bernardo; GÁLVEZ HERRER, Macarena; GARROSA HERNÁNDEZ, Eva; RODRÍGUEZ CARVAJAL, Raquel. La adiccion al trabajo. Psicología Conductual, v. 13, n. 3, 417-428. 2005. Disponível em: http://uam.es/gruposinv/esalud/Articulos/Salud\%20Laboral/2005LA-ADICCION-AL-TRABAJO.pdf

MORIN, Estelle M. Os sentidos do trabalho. RAE -Revista de Administração de Empresas, São Paulo, v. 41, n. 3, jul./set. 2001. Disponível em: <http://www.scielo.br/pdf/rae/v41n3/v41n3a02.pdf>. Acesso em: 13 ago. 2015.

NEWSTROM, John W. Comportamento organizacional: O Comportamento Humano no Trabalho. 12. ed. PortoAlegre: McGraw-Hill, 2008.

NOBRE, Thalita Lacerda. Motivação: os desafios da gestão de recursos humanos na atualidade. Curitiba, PR: Juruá, 2011.

OLIVER, Marilene et al. Profissionais de sucesso, vida paradoxal: consequências das novas exigências organizacionais. In: IX Convibra Administração - Congresso Virtual Brasileiro de Administração, 2004. Disponível em: <http://www.convibra.org/upload/paper/2012/34/2012_34_5034.pdf>. Acesso em: 12 abr. 2016.

PEREIRA, Eliane França; TOLFO, Suzana Tolfo Rosa. Estudos sobre sentidos e significados do trabalho na psicologia: uma revisão das suas bases teóricoepistemológicas. Psicologia Argumento, v. 34, n. 87, 2017.

PINTO, Marcelo Pádua Carvalho. Comportamento organizacional: um estudo de suas relações com desempenho na carreira. Belo Horizonte: Universidade FUMEC, 2011. Disponível em:

<http://www.fumec.br/anexos/cursos/mestrado/dissertacoes/completa/marcelo_padua_carvalho.pdf >.Acesso em: 17 ago. 2015.

PORTER, Gayle; KAKABADSE, Nada K. HRM perspectives on addiction to technology and work. Journal of Management Development, v. 25, n. 6, p. 535-560, 2006. http://dx.doi.org/10.1108/02621710610670119

RANTANEN, Johanna et al. Cross-national and longitudinal investigation of a short measure of workaholism. Industrial health, v. 53, n. 2, p. 113-123, 2015. Disponível em: https://www.jniosh.go.jp/en/indu_hel/doc/lH_53_2_113.pdf. Acesso em: 15 fev. 2017 
REBELLO, G. (2002). A nova cultura do trabalho e do emprego: que desafios para os actores sociais? Dinâmia. Centro de Estudos sobre a mudança socieconomica. Lisboa: ISCTE. Recuperado 10 novembro, 2008, de <http://loki.iscte.pt:8080/dspace/bitstream/10071/483/1/wp23-2002.pdf>.

RESTREPO, Jaime Hernán Arroyave. Adiccion al trabajo. In: IV Congresso Internacional de Adicciones de lãs Drogas a lãs dependencias no quimicas. Medellin, 1 y 2 de dic. 2011. Disponível em:

$<$ http://virtual.funlam.edu.co/repositorio/sites/default/files/repositorioarchivos/2012/02/PonenciaDrJaimeArroyave.1284.p df>. Acessoem: 6 ago. 2015.

ROBBINS, Stephen P. Comportamento organizacional. 11. ed. São Paulo: Pearson Prentice Hall, 2005.

SAMPIERI, Roberto Hernández; COLADO, Carlos Fernández; e LUCIO, Pilar Baptista. Metodologia de Pesquisa. São Paulo: Mc-Graw-Hill, $3^{\mathrm{a}}$ ed, 2006.

SCHAUFELI, Wilmar B.; TARIS, Toon W.; BAKKER, Arnold B. It takes two to tango. Workaholism is working excessively and working compulsively. The long work hours culture. Causes, consequences and choices, p. 203-226, 2008.

Disponível em: https://books.google.com.br/books?hl=pt-

BR\&lr=\&id=AJXnY9lqYvoC\&oi=fnd\&pg=PA203\&dq=Schaufeli,+Taris+e+Bakker+(2008)\&ots=owKyqT9q5R\&sig=YC2FIG E_uBYGAvBqkdogP5pjLts\#v=onepage\&q=Schaufeli\%2C\%20Taris\%20e\%20Bakker\%20(2008)\&f=false Acesso em 09 jul. 2017.

SERVA, M.; FERREIRA, J. O fenômeno workaholic na gestão de empresas. RAP - Revista de Administração Pública, Rio de Janeiro, v. 40, n. 2, p. 179-198,mar./abr. 2006. Disponível em:

<http://www.scielo.br/pdf/rap/v40n2/v40n2a02.pdf>. Acesso em: 6 ago. 2015.

SHIMAZU, Akihito; SCHAUFELI, Wilmar B. Is workaholism good or bad for employee well-being? The distinctiveness of workaholism and work engagement among Japanese employees. Industrial health, v. 47, n. 5, p. 495-502, 2009. Disponível em: https://pdfs.semanticscholar.org/d5eb/5dd48d520ab1b9e0049359edbc010fb1c501.pdf. Acesso em 02 fev. 2017.

SILVA, Caroline Machado Castilhos da; PEIXOTO, Roberta Ramalho; BATISTA, José Mauro Ruiz. A influência da liderança na motivação da equipe. Revista Eletrônica Novo Enfoque, [S.I.], v. 13, n. 13, p. 195-206, 2011. Disponível em: <http://castelobranco.br/sistema/novoenfoque/files/13/artigos/17_RobertaeCaroline_ProfRuiz_VF.pdf>. Acesso em: 7 abr. 2016.

STEFANICZEN, Josemara; STEFANO, Silvio Roberto; MACHADO, Roseli de Oliveira. Workaholic: Um novo modelo de comportamento nas organizações. In: XII SEMEAD, set. 2010. Disponível em:

<http://www.ead.fea.usp.br/semead/13semead/resultado/trabalhospdf/472.pdf>. Acesso em: 6 ago. 2015.

SUSSMAN, Steven. Workaholism: A review. Journal of addiction research \& therapy, n. 141, v. 4, 2012. Disponível em: http://europepmc.org/articles/pmc3835604. Acesso em 26 fev. 2017.

TARIS, Toon W.; VAN BEEK, Ilona; SCHAUFELI, Wilmar B. Demographic and occupational correlates of workaholism. Psychological reports, v. 110, n. 2, p. 547-554, 2012.

WOOD JR., Thomaz (Coord.). Gestão empresarial: comportamento organizacional. São Paulo: Atlas, 2005.

ZANELLI, José Carlos; BORGES-ANDRADE, Jairo Eduardo; BASTOS, Antonio Virgílio Bittencourt (Orgs.). Psicologia, organizações e trabalho no Brasil. Porto Alegre: Artmed, 2014.

ZANELLI, José Carlos; SILVA, Narbal; TOLFO, Suzana da Rosa. Processos psicossociais nas organizações e no trabalho. São Paulo: Casa do Psicólogo, 2011.

ZARATINI, Alexei José; PADILHA, Valquíria. Trabalho e tempo livre: um estudo sobre qualidade de vida no trabalho com gerente do setor hoteleiro. FACEF Pesquisa, [S.I.], v.13, n.2, 2010. Disponível em:

<http://periodicos.unifacef.com.br/index.php/facefpesquisa/article/viewFile/242/234>. Acesso em: 22 mar. 2016. 